\title{
Evaluation of the Prevalence of Iodine Intakes above the Tolerable Upper Intake Level from Four 3-Day Dietary Records in a Japanese Population
}

\author{
Megumi Tsubota-Utsugi ${ }^{1,2}$, Eri ImaI ${ }^{1}$, Makiko NAKADE ${ }^{1}$, Teruki Matsumoto ${ }^{3}$, \\ Nobuyo TSUBOYAMA-KASAOKA ${ }^{1}$, Nobuo NISHI $^{2}$ and Yoshitaka TSUBONO ${ }^{4}$ \\ ${ }^{1}$ Section of the Dietary Reference Intakes, Department of Nutritional Epidemiology, \\ ${ }^{2}$ Center for International Collaboration and Partnership, and ${ }^{3}$ Department of Food Function and \\ Labeling, National Institute of Health and Nutrition, Tokyo 162-8636, Japan \\ ${ }^{4}$ Yamagata Sakura-machi Hospital, Yamagata 990-0045, Japan
}

(Received January 28, 2013)

\begin{abstract}
Summary The Japanese population routinely consumes iodine-rich seaweed, thereby probably making Japan the nation with the highest iodine intake worldwide. The present study aimed to estimate the duration of dietary records (DRs) needed to calculate the usual iodine intake and to ascertain the frequency of iodine intakes above the tolerable upper intake level (UL) in the Dietary Reference Intakes for Japanese. Four 3-d DRs for the 4 seasons within a year were collected for 55 men and 58 women. On the basis of analysis of variance, the total variance in iodine intake was classified into inter-individual and intraindividual components. The frequency of appearance for high iodine intakes was estimated. The most commonly consumed types of iodine-containing food items were seaweed, milk and milk products, fish and shellfish, and tofu. The percentage contribution of intra-individual variance was markedly greater than that of inter-individual variance, and the excessive iodine intake was intermittent rather than continuous. The duration for which dietary records were required to assess the usual intake of iodine within $10 \%$ of their true mean was $6,276 \mathrm{~d}$ for men and $4,953 \mathrm{~d}$ for women. The period that transpired until a value was exceeded once was $6.3 \mathrm{~d} /$ occurrence for values above UL $(2,200 \mu \mathrm{g}), 8.5 \mathrm{~d} /$ occurrence for values above 3,000 $\mu \mathrm{g}, 9.8 \mathrm{~d} /$ occurrence for values above 4,000 $\mu \mathrm{g}, 11.2 \mathrm{~d} /$ occurrence for values above 5,000 $\mu \mathrm{g}$, and $16.7 \mathrm{~d} /$ occurrence for values above $10,000 \mu \mathrm{g}$. To avoid errors in interpretation, it is inappropriate to assess the habitual nutrient intake of a nutrient that is intermittently consumed at maximal levels. It is important to assess the iodine intake in consideration of the range of the nutrient intake and of the time period in which the upper limit is exceeded.
\end{abstract}

Key Words Japanese, iodine intake, dietary records, the tolerable upper intake level, Dietary Reference Intakes for Japanese

Iodine deficiency is considered to be one of the most common nutritional disorders worldwide (1) and the most common cause of goiter. However, the Japanese population routinely consumes iodine-rich seaweed products; this might result in disorders related to excess intake of iodine through the consumption of meals and between-meal snacks prepared using seaweed. It has been reported that iodine intakes by the Japanese are typically in the range of $1,000-3,000 \mu \mathrm{g} / \mathrm{d}(2-5)$. However, these studies were reported for a given day and not as a mean of several days.

Moreover, high iodine intakes can cause disturbances in thyroid function $(6,7)$. Because of the assumption that most Japanese individuals have experienced iodine escape $(8,9)$, the tolerable upper intake levels (UL) of the Dietary Reference Intakes for Japanese (DRIs-J 2010) of $2,200 \mu \mathrm{g} / \mathrm{d}$ is relatively high compared with that of other countries $(500-1,100 \mu \mathrm{g} / \mathrm{d})$, as presented

E-mail: mutsugky@nih.go.jp in Appendix 1 (10-16).

Iodine status has traditionally been assessed using urinary iodide excretion or goiter rate, which is calculated on the basis of thyroid gland size (17). Although measurement of urinary iodine excretion is usually sufficient when conducting population-based studies, such data are scarce. Estimating the distribution of the normal dietary intake in the population using dietary record(s) (DRs) and 24-h dietary recall is generally used in surveys (18).

The aims of this study were to provide an estimate of the number of days needed to accurately calculate the usual iodine intake and to ascertain the frequency of iodine intakes above UL provided in DRIs-J 2010.

\section{MATERIALS AND METHODS}

Study design and subjects. The data set for this study was obtained from data originally collected to assess the validity and reproducibility of a food frequency questionnaire used in 3 large-scale cohort studies on cancer 
(19). The subjects of the present study were the residents of two rural towns in Miyagi Prefecture in the northern part of Japan. A total of 59 male and 60 female participants (mean age 62.5 and $61.2 \mathrm{y}$, respectively) were selected on a voluntary basis. In the present study, only those participants who provided information for intake data for all $12 \mathrm{~d}$ of data collection were included. Thus, data from 113 participants ( 55 men and 58 women) were analyzed.

DRs. Standardized methodology was used to calculate energy and nutrient intakes. DRs were collected using 3-d DRs as a reference method during each of the 4 seasons over a period of $1 \mathrm{y}$ : in the month of November (autumn) 1996 and in February (winter), May (spring), and August (summer) 1997 (20, 21).

The participants were instructed to record all food items and beverages consumed in a standardized booklet. They were asked to provide detailed descriptions of each food item (open ended), including the weights prepared and proportions consumed. Research dieticians assessed the records in a standardized manner after completion by the participants. Iodine intake was calculated from these records using the Japanese Standard Food Composition Table 2010 (22) published by the Ministry of Education, Culture, Sports, Science and Technology. To avoid arbitrariness, we presented the results based on items from the Food Composition Table 2010. The iodine intake values were reported only for $34.1 \%(642 / 1,878$ items) of the total food items in the Food Composition Table 2010. Moreover, we did not complement the missing values by using other resources to avoid introducing variability in the measurement method used in this study.

Data analyses. All the analyses were performed using SAS software (version 9.3 SAS Institute Inc., Cary, NC, USA).

(1) Estimation of the duration needed to record accurate iodine intake: The total iodine intake was classified on the basis of analysis of variance into the following 2 classes: (1) inter-individual variance in the subjects' usual intake and (2) residual variance, which represents the intra-individual variability in daily intake.

Estimates of within-person $\left(\sigma_{\mathrm{w}}^{2}\right)$ and between-person variances $\left(\sigma_{\mathrm{b}}^{2}\right)$ were calculated by setting mean squares (MS) equal to their expected values. The values for $\left(\sigma_{\mathrm{w}}^{2}\right)$ and $\sigma_{\mathrm{b}}^{2}$ were estimated from the following equations:

$$
\begin{aligned}
& \mathrm{MS}_{\mathrm{w}}=\sigma_{\mathrm{w}}^{2} \\
& \sigma_{\mathrm{b}}^{2}=\left(\mathrm{MS}_{\mathrm{b}}-\sigma_{\mathrm{w}}^{2}\right) / c \\
& c=\left(N-\Sigma_{n i}^{2} / N\right) /(a-1)
\end{aligned}
$$

Here " $a$ " is the number of subjects, ni is the number of days for which DRs provided by the $i$-th subject were available, and $N=\Sigma_{n i}^{2}$ is the total number of days for which DRs were available from all the subjects. All the calculations were performed using the SAS variance component procedure in the PROC VARCOMP application. This was used to calculate the ratios of within-person and between-person variance $\left(\sigma_{\mathrm{w}}^{2} / \sigma_{\mathrm{b}}^{2}\right)$.

In addition, the number of days required to estimate an individual's true iodine intake with $95 \%$ confidence intervals within $10 \%$ and $20 \%$ of their true mean was

\begin{tabular}{|c|c|c|c|}
\hline Top & $\begin{array}{c}\text { Food item } \\
\text { number }\end{array}$ & Food and description & $\begin{array}{l}\mu \mathrm{g} / \mathrm{d} \cdot \\
\text { person }\end{array}$ \\
\hline 1 & 9017 & Ma-konbu dried & $1,102.7$ \\
\hline 2 & 9020 & Kizami-konbu & 559.9 \\
\hline 3 & 9015 & Naga-konbu dried & 302.8 \\
\hline 4 & 9031 & Hijiki boiled and dried & 159.3 \\
\hline 5 & 9023 & Konbu Tsukudani & 93 \\
\hline 6 & 9045 & Wakame blanched and desalted & 50 \\
\hline 7 & 13003 & Ordinary liquid milk & 17 \\
\hline 8 & 10205 & Pacific cod raw & 10.6 \\
\hline 9 & 2004 & Konjac block & \\
\hline 10 & 9004 & Purple laver toasted & 7.8 \\
\hline 11 & 9039 & Wakame dried & 7.8 \\
\hline 12 & 9026 & Tengusa Tokoroten & 3.6 \\
\hline 13 & 13026 & Yogurt skimmed and sweetened & \\
\hline 14 & 10087 & Skipjack caught in autumn, raw & \\
\hline 15 & 10292 & Oysters cultured and raw & 1.9 \\
\hline 16 & 10202 & Tarako: walleye pollack, raw & 1.4 \\
\hline 17 & 4032 & Tofu: momen-tofu & 1.2 \\
\hline 18 & 10253 & Bluefin tuna lean meat and raw & 1.1 \\
\hline 19 & 10070 & Japanese eel Kabayaki & 1.1 \\
\hline 20 & 6134 & Daikon root without skin and raw & \\
\hline 21 & 10173 & Pacific saury, raw & 0.9 \\
\hline 22 & 18001 & Curry beef and retort-pouched dishes & 0.8 \\
\hline 23 & 16006 & Beer pale & 0.8 \\
\hline 24 & 9047 & Wakame fruit-bearing leaves and raw & 0.8 \\
\hline 25 & 10100 & Brown sole, raw & 0.7 \\
\hline 26 & 10281 & Short-necked clams, raw & 0.7 \\
\hline 27 & 10174 & Pacific saury baked & 0.6 \\
\hline 28 & 15060 & Rice crackers Shio-senbei & 0.6 \\
\hline 29 & 13025 & Yogurt whole milk and unsweetened & 0.5 \\
\hline 30 & 9002 & Green laver dried & 0.5 \\
\hline
\end{tabular}

Table 1. The top 30 items which contribute to the high iodine intake in the present subjects.

${ }^{1}$ Item numbers were addressed under the Food Composition Table 2010.

calculated, using the following formula (23): $n=\left(\mathrm{Z}_{\alpha} \mathrm{CV}_{\mathrm{w}} / D_{0}\right)^{2}$

Here $n=$ the number of days required per person, $\mathrm{Z}_{\alpha}=1.96, \mathrm{CV}_{\mathrm{w}}=$ the within-person coefficient of variation $(\%)$, and $D_{0}=$ the specific degree of error expressing a percentage of long-term true iodine intake $(10 \%$ or $20 \%$ ). All the analyses were performed separately for male and female subjects.

(2) Estimation of the frequency of appearance above UL: The frequency of occurrence of high iodine intake was estimated for the following 5 different values: (a) above UL, i.e., 2,200 $\mu \mathrm{g} / \mathrm{d}$ provided in the current DRIsJ 2010; (b) above 3,000 $\mu \mathrm{g} / \mathrm{d}$; (c) above 4,000 $\mu \mathrm{g} / \mathrm{d}$; (d) above $5,000 \mu \mathrm{g} / \mathrm{d}$; and (e) above $10,000 \mu \mathrm{g} / \mathrm{d}$, from the data of all 12 assessment days throughout a 1-y period. Among the 1,356 person-days of the subjects, the frequencies at which the each intake exceeded five different values were tabulated and converted to the occurrence period. For example, there were 216 occurrences of iodine level above $2,200 \mu \mathrm{g} / \mathrm{d}$ which is equivalent to $1,356 / 216=6.3 \mathrm{~d}$ per occurrence. Given the considerable difference between intra-individual and interindividual variance for iodine, the frequency of peak 
Table 2-1. Ratios of intra- and inter-individual variance and the number of repeated dietary records per individual needed to assure that the efficiency of estimation of the true iodine intake is within $10 \%$ and $20 \%$ of the true mean in men.

\begin{tabular}{|c|c|c|c|c|c|c|c|c|}
\hline & \multirow{2}{*}{$\begin{array}{l}\text { Mean } \\
\text { intake }\end{array}$} & \multicolumn{2}{|c|}{$\begin{array}{l}\text { Percentage contribution of } \\
\text { variance components }\end{array}$} & \multirow{2}{*}{$\begin{array}{l}\text { Intra-/Inter- } \\
\text { individual }\end{array}$} & \multicolumn{2}{|c|}{ Coefficient of variation } & \multirow{2}{*}{$\begin{array}{l}10 \%^{1} \\
(\mathrm{~d})\end{array}$} & \multirow{2}{*}{$\begin{array}{l}20 \%^{2} \\
\text { (d) }\end{array}$} \\
\hline & & $\begin{array}{c}\text { Intra- } \\
\text { individual }\end{array}$ & $\begin{array}{c}\text { Inter- } \\
\text { individual }\end{array}$ & & Intra- $(\%)$ & Inter- $(\%)$ & & \\
\hline Energy (kcal) & 2,545 & 48.1 & 51.9 & 0.9 & 17.5 & 18.2 & 12 & 3 \\
\hline Protein $(\mathrm{g})$ & 94 & 68.1 & 31.9 & 2.1 & 22.6 & 15.5 & 20 & 5 \\
\hline Fat $(\mathrm{g})$ & 56 & 76.8 & 23.2 & 3.3 & 317.8 & 20.8 & 55 & 14 \\
\hline Carbohydrates (g) & 362 & 45.3 & 54.7 & 0.8 & 18 & 19.8 & 12 & 3 \\
\hline \multicolumn{9}{|l|}{ Vitamin } \\
\hline Vitamin A $(\mu \mathrm{g} R E)^{*}$ & 361 & 98.3 & 1.7 & 56.9 & 254.7 & 33.8 & 2,491 & 623 \\
\hline Vitamin D $(\mu \mathrm{g})$ & 13.9 & 89.4 & 10.6 & 8.4 & 82.9 & 28.5 & 264 & 66 \\
\hline Vitamin E (mg) & 8.1 & 77.8 & 22.2 & 3.5 & 36.6 & 19.6 & 52 & 13 \\
\hline Vitamin K $(\mu \mathrm{g})$ & 337 & 74.2 & 25.8 & 2.9 & 54.4 & 32 & 114 & 28 \\
\hline Vitamin $B_{1}(\mathrm{mg})$ & 1 & 85.4 & 14.6 & 5.9 & 39.6 & 16.4 & 60 & 15 \\
\hline Vitamin $B_{2}(\mathrm{mg})$ & 1.6 & 75.4 & 24.6 & 3.1 & 31.3 & 17.9 & 38 & 9 \\
\hline Niacin $(\mathrm{mg})$ & 21 & 76.3 & 23.7 & 3.2 & 41.2 & 23 & 65 & 16 \\
\hline Vitamin $B_{6}(\mathrm{mg})$ & 2 & 71.5 & 28.5 & 2.5 & 31.2 & 19.7 & 37 & 9 \\
\hline Vitamin $\mathrm{B}_{12}(\mu \mathrm{g})$ & 13 & 88 & 12 & 7.3 & 79.6 & 29.4 & 244 & 61 \\
\hline Folate $(\mu \mathrm{g})$ & 424 & 73 & 27 & 2.7 & 32.7 & 19.9 & 41 & 10 \\
\hline Pantothenic acid (mg) & 8 & 60.3 & 39.7 & 1.5 & 23.2 & 18.8 & 21 & 5 \\
\hline Biotin $(\mu \mathrm{g})$ & 37 & 84.6 & 15.4 & 5.5 & 44.6 & 19 & 76 & 19 \\
\hline Vitamin C (mg) & 120 & 78.3 & 21.7 & 3.6 & 49 & 25.8 & 92 & 23 \\
\hline \multicolumn{9}{|l|}{ Mineral } \\
\hline Sodium (mg) & 5,648 & 73.7 & 26.3 & 2.8 & 28 & 16.7 & 30 & 8 \\
\hline Potassium (mg) & 3,218 & 69.5 & 30.5 & 2.3 & 26.5 & 17.5 & 27 & 7 \\
\hline Calcium (mg) & 679 & 63.7 & 36.3 & 1.8 & 35.5 & 26.8 & 48 & 12 \\
\hline Magnesium (mg) & 369 & 71 & 29 & 2.4 & 25.7 & 16.4 & 25 & 6 \\
\hline Phosphorus (mg) & 1,392 & 65 & 35 & 1.9 & 22.5 & 16.5 & 19 & 5 \\
\hline Iron $(\mathrm{mg})$ & 11.2 & 75.7 & 24.3 & 3.1 & 28.6 & 16.2 & 31 & 8 \\
\hline Zinc (mg) & 11 & 70.9 & 29.1 & 2.4 & 26.7 & 17.1 & 27 & 7 \\
\hline Copper (mg) & 1.8 & 82.2 & 17.8 & 4.6 & 37.2 & 17.3 & 53 & 13 \\
\hline Manganese (mg) & 5.2 & 53.7 & 46.3 & 1.2 & 24.2 & 22.5 & 22 & 6 \\
\hline Iodine $(\mu \mathrm{g})$ & 2,550 & 98.6 & 1.4 & 70.2 & 404.2 & 48.2 & 6,276 & 1,569 \\
\hline Selenium $(\mu \mathrm{g})$ & 74 & 89 & 11 & 8.1 & 69.5 & 24.4 & 185 & 46 \\
\hline Chromium $(\mu \mathrm{g})$ & 7 & 85.5 & 14.5 & 5.9 & 50 & 20.6 & 96 & 24 \\
\hline Molybdenum $(\mu \mathrm{g})$ & 289 & 54.1 & 45.9 & 1.2 & 28.7 & 26.4 & 32 & 8 \\
\hline
\end{tabular}

*Vitamin $\mathrm{A}(\mu \mathrm{g} \mathrm{RE})=$ retinol $(\mu \mathrm{g})+\beta$-carotene $(\mu \mathrm{g}) \times 1 / 12+\alpha$-carotene $(\mu \mathrm{g}) \times 1 / 24+\beta$-cryptxanthin $(\mu \mathrm{g}) \times 1 / 24+$ other provitamin A carotenoids $(\mu \mathrm{g}) \times 1 / 24$.

${ }^{1}$ The number of the days of collecting food record which would be required to estimate the true intake within $10 \%$ of their true mean with $95 \%$ confidence.

${ }^{2}$ The number of the days of collecting food record which would be required to estimate the true intake within $20 \%$ of their true mean with $95 \%$ confidence.

iodine intake among the subjects was estimated as the frequency of peak iodine intake by individuals. The data for both genders were combined for this analysis.

\section{RESULTS}

In this study, 113 participants (55 men and 58 women) provided information regarding intake data for all $12 \mathrm{~d}$ of data collection; only these data were analyzed in the study.

The male subjects were aged 45-77 y [mean \pm standard deviation (SD): $62+9 \mathrm{y}]$ and the female subjects were aged 47-76 y (mean \pm SD: $61 \pm 9$ y). By occupation, most participants were farmers, self-employed, or housewives. The percentage of current smokers in men was $49.1 \%$ (27 subjects); no current smokers were present among the women. The mean/median iodine intake data for 3 consecutive days in each season were $2,659 / 140 \mu \mathrm{g} / \mathrm{d}$ in spring, 1,616/107 $\mu \mathrm{g} / \mathrm{d}$ in summer, $2,125 / 116 \mu \mathrm{g} / \mathrm{d}$ in autumn, and $2,999 / 163 \mu \mathrm{g} / \mathrm{d}$ in winter.

\section{Dietary sources and intake}

Table 1 presents the top 30 food sources that contributed to high iodine intake in the study subjects. In this study, the most commonly consumed iodine-containing food was seaweed (konbu, hijiki, wakame, and nori), followed by milk and milk products, fish and shellfish (codfish, bonito, tuna, giant pacific oyster, and eel) and tofu. However, the iodine content of other food items was 
Table 2-2. Ratios of intra- and inter-individual variance and the number of repeated dietary records per individual needed to assure that the efficiency of estimation of the true iodine intake is within $10 \%$ and $20 \%$ of the true mean in women.

\begin{tabular}{|c|c|c|c|c|c|c|c|c|}
\hline & \multirow{2}{*}{$\begin{array}{l}\text { Mean } \\
\text { intake }\end{array}$} & \multicolumn{2}{|c|}{$\begin{array}{l}\text { Percentage contribution of } \\
\text { variance components }\end{array}$} & \multirow{2}{*}{$\begin{array}{l}\text { Intra-/Inter- } \\
\text { individual }\end{array}$} & \multicolumn{2}{|c|}{ Coefficient of variation } & \multirow{2}{*}{$\begin{array}{c}10 \%^{1} \\
(\mathrm{~d})\end{array}$} & \multirow{2}{*}{$\begin{array}{c}20 \%^{2} \\
\text { (d) }\end{array}$} \\
\hline & & $\begin{array}{c}\text { Intra- } \\
\text { individual }\end{array}$ & $\begin{array}{c}\text { Inter- } \\
\text { individual }\end{array}$ & & Intra- $(\%)$ & Inter- (\%) & & \\
\hline Energy (kcal) & 1,977 & 66.3 & 33.7 & 2 & 17.3 & 12.4 & 12 & 3 \\
\hline Protein $(\mathrm{g})$ & 80 & 72.5 & 27.5 & 2.6 & 23.4 & 14.4 & 21 & 5 \\
\hline Fat $(\mathrm{g})$ & 53 & 79.8 & 20.2 & 3.9 & 33.9 & 17.1 & 44 & 11 \\
\hline Carbohydrates (g) & 290 & 59.3 & 40.7 & 1.5 & 17.4 & 14.4 & 12 & 3 \\
\hline \multicolumn{9}{|l|}{ Vitamin } \\
\hline Vitamin A ( $\mu \mathrm{g} \mathrm{RE})^{*}$ & 304 & 100 & 0 & $\infty$ & 307.5 & 0 & 3,633 & 908 \\
\hline Vitamin D $(\mu \mathrm{g})$ & 11 & 91.8 & 8.2 & 11.1 & 80.6 & 24.1 & 249 & 62 \\
\hline Vitamin E (mg) & 8.3 & 75.5 & 24.5 & 3.1 & 33.8 & 19.3 & 44 & 11 \\
\hline Vitamin $\mathrm{K}(\mu \mathrm{g})$ & 315 & 81.2 & 18.8 & 4.3 & 52.3 & 25.2 & 105 & 26 \\
\hline Vitamin $\mathrm{B}_{1}(\mathrm{mg})$ & 0.9 & 82.3 & 17.7 & 4.6 & 31.7 & 14.7 & 39 & 10 \\
\hline Vitamin $B_{2}(\mathrm{mg})$ & 1.6 & 71.6 & 28.4 & 2.5 & 28 & 17.6 & 30 & 8 \\
\hline Niacin (mg) & 18 & 78.2 & 21.8 & 3.6 & 40.8 & 21.6 & 64 & 16 \\
\hline Vitamin $\mathrm{B}_{6}(\mathrm{mg})$ & 1 & 76.3 & 23.7 & 3.2 & 29.7 & 16.5 & 34 & 8 \\
\hline Vitamin $\mathrm{B}_{12}(\mu \mathrm{g})$ & 11 & 89 & 11 & 8.1 & 87 & 30.6 & 291 & 73 \\
\hline Folate $(\mu \mathrm{g})$ & 435 & 67.8 & 32.2 & 2.1 & 31.9 & 22 & 39 & 10 \\
\hline Pantothenic acid (mg) & 7 & 68.1 & 31.9 & 2.1 & 23.3 & 15.9 & 21 & 5 \\
\hline Biotin $(\mu \mathrm{g})$ & 33 & 87.9 & 12.1 & 7.2 & 44.8 & 16.7 & 77 & 19 \\
\hline Vitamin C (mg) & 141 & 71.8 & 28.2 & 2.6 & 42 & 26.3 & 68 & 17 \\
\hline \multicolumn{9}{|l|}{ Mineral } \\
\hline Sodium (mg) & 5,079 & 73.6 & 26.4 & 2.8 & 28.2 & 16.9 & 31 & 8 \\
\hline Potassium (mg) & 3,131 & 67.8 & 32.2 & 2.1 & 24.2 & 16.7 & 23 & 6 \\
\hline Calcium (mg) & 665 & 66.9 & 33.1 & 2 & 32.7 & 23 & 41 & 10 \\
\hline Magnesium (mg) & 328 & 71.6 & 28.4 & 2.5 & 25 & 15.7 & 24 & 6 \\
\hline Phosphorus (mg) & 1,215 & 70.9 & 29.1 & 2.4 & 22.8 & 14.6 & 20 & 5 \\
\hline Iron $(\mathrm{mg})$ & 10.6 & 71.2 & 28.8 & 2.5 & 28.7 & 18.2 & 32 & 8 \\
\hline Zinc (mg) & 9 & 78.8 & 21.2 & 3.7 & 29.2 & 15.1 & 33 & 8 \\
\hline Copper (mg) & 1.5 & 75.6 & 24.4 & 3.1 & 25.3 & 14.3 & 25 & 6 \\
\hline Manganese (mg) & 4.8 & 63.1 & 36.9 & 1.7 & 26.6 & 20.3 & 27 & 7 \\
\hline Iodine $(\mu \mathrm{g})$ & 2,160 & 96.7 & 3.3 & 29.8 & 359.1 & 65.8 & 4,953 & 1,238 \\
\hline Selenium $(\mu \mathrm{g})$ & 63 & 87.1 & 12.9 & 6.7 & 69.1 & 26.6 & 183 & 46 \\
\hline Chromium $(\mu \mathrm{g})$ & 7 & 88.5 & 11.5 & 7.7 & 47.4 & 17.1 & 86 & 22 \\
\hline Molybdenum $(\mu \mathrm{g})$ & 215 & 77.4 & 22.6 & 3.4 & 31.5 & 17 & 38 & 10 \\
\hline
\end{tabular}

${ }^{*} \operatorname{Vitamin} \mathrm{A}(\mu \mathrm{g} \mathrm{RE})=$ retinol $(\mu \mathrm{g})+\beta$-carotene $(\mu \mathrm{g}) \times 1 / 12+\alpha$-carotene $(\mu \mathrm{g}) \times 1 / 24+\beta$-cryptxanthin $(\mu \mathrm{g}) \times 1 / 24+$ other provitamin A carotenoids $(\mu \mathrm{g}) \times 1 / 24$.

${ }^{1}$ The number of the days of collecting food record which would be required to estimate the true intake within $10 \%$ of their true mean with $95 \%$ confidence.

${ }^{2}$ The number of the days of collecting food record which would be required to estimate the true intake within $20 \%$ of their true mean with $95 \%$ confidence.

low. None of the subjects reported an iodine intake of $0 \mu \mathrm{g} / \mathrm{d}$, whereas higher iodine intakes occurred at intervals depending on which food items the subject had consumed on a particular day. For example, the three subjects who presented the highest iodine intake, exceeding $120,000 \mu \mathrm{g} / \mathrm{d}$ over all the observation days, consumed konbu on the third assessment day in autumn, whereas on other days, they did not consume high iodine-containing food items (data not shown).

Time period required to assess usual iodine intake

Table 2-1 (males) and Table 2-2 (females) present the ratio of intra-individual and inter-individual coefficients of variation and the number of days with the available DR data required to assess the usual intake, with an error margin within the specified limits $(10 \%$ and $20 \%$ ). The percentage contribution of intra-individual variance was markedly larger compared with that of inter-individual variance. Therefore, the ratio of intraindividual and inter-individual coefficients of variation was large. Compared with other nutrients, the time period for which DRs were required to assess the usual intake of iodine within $10 \%$ of their true mean was extensive (within 10\%: 6,276 d for males and 4,953 d for females).

Estimation of the frequency at which UL is exceeded

The frequency at which the selected values were exceeded decreased as the value increased. The period that transpired until a value was exceeded once was 
$6.3 \mathrm{~d}$ /occurrence for values above UL, $8.5 \mathrm{~d}$ /occurrence for values above 3,000 $\mu \mathrm{g}, 9.8 \mathrm{~d}$ /occurrence for values above $4,000 \mu \mathrm{g}, 11.2 \mathrm{~d} /$ occurrence for values above $5,000 \mu \mathrm{g}$, and $16.7 \mathrm{~d}$ /occurrence for values above $10,000 \mu \mathrm{g}$.

\section{DISCUSSION}

The current study indicates that the number of days for which DRs are required to assess the mean iodine intake is not feasible in standard study time frames. The percentage contribution of intra-individual variance was markedly greater than that of inter-individual variance, and excessive iodine intake was intermittent rather than continuous. The UL $(2,200 \mu \mathrm{g})$ was exceeded approximately once a week in this study group.

Are there Japanese individuals who consume iodine in excess of the UL?

DRIs-J states that the UL presents the highest level of habitual iodine intake that is considered to pose no risk of adverse health effects to virtually any healthy individuals. As long as the daily intake is obtained from food items and beverages, rather than from supplements, this intake value is unlikely to be exceeded $(15,24)$. However, long-term intakes above the UL increase the risk of health problems.

In the present study, we observed that Japanese individuals habitually but intermittently consumed high quantities of iodine from food, and iodine intake among the subjects was estimated to exceed the UL once a week. The frequency at which the UL was exceeded decreased in association with an increase in the value; however, even individuals with iodine intake of more than $10,000 \mathrm{mg}$ once every $2 \mathrm{wk}$ were reported.

It is important to note that during nutritional surveys or other activities aimed at diet improvement or food services management, the nutrient intake values are usually computed from the raw weight of food items before cooking and processing and not from the actual quantity consumed. Furthermore, most food items with high iodine levels are usually used for preparing soup stock and are not consumed directly in their raw forms $(25,26)$ such as konbu, which has the highest levels of iodine. Because it is usually used for preparing soup stock or is consumed as a tsukudani (konbu boiled in soy sauce), most of the iodine strains out from the soup and little iodine is actually consumed from this source. Consequently, true iodine intake in traditional Japanese dishes is estimated to be approximately $10-50 \%$ of the usual iodine intake calculated by DRs $(25,26)$.

In recent years, there has been a growing concern regarding disorders caused by excessive iodine intake through the consumption of between-meal snacks prepared using seaweed, particularly those prepared using konbu, which are popular in Japan (27). Thus, the excessive iodine intake from between-meal snacks, in parallel with high iodine intake from normal meals in the Japanese culture, needs to be carefully monitored. As long as the iodine intake is primarily obtained from food items and beverages, the proportion of individuals with an iodine intake above the UL is likely to be less than that presumed at the present time. However, the possibility that there are individuals with iodine intake above these levels cannot be denied.

Special care needed for assessment and interpretation of iodine intake

In general, the fewer the number of observation days, the broader the intake distribution. We observed that DRs for an extended period of time were required to characterize the long term mean iodine intake in this population. Accordingly, estimation of deficient or excessive iodine intake from short term DRs leads to overestimation or underestimation, which thereby leads to increased risk of misperceptions. However, considering the burden placed on the participants, obtaining data over a longer period of time is not feasible in epidemiological settings or nutrition surveys. The present study results suggest that excessive consumption of iodine is dependent on particular food items and that high iodine intake is intermittent rather than continuous. For this reason, it is inappropriate to assess the habitual nutrient intake of a particular nutrient that is consumed at high levels only intermittently. For estimating or interpreting the intermittent intake of nutrients such as iodine in epidemiological settings or nutrition surveys, including NHNS-J, it is necessary to determine not only the mean or median intake but also the range of the nutrient intake, and the time period until the value (i.e., UL provided by DRIs-J) is exceeded. In addition, careful consideration should be given to the food items that are consumed and the frequency at which they are consumed. Further investigation and evidence with detailed long term data regarding foods, doses, and patterns of iodine intakes for a large number of participants are required to confirm the value of iodine intake for DRIs-J.

\section{Study limitations}

Several limitations of this study need to be discussed. First, as mentioned earlier, iodine intake was calculated from the data using the Japanese Standard Food Composition Table published in 2010 (22), but iodine values were reported for only $34.1 \%$ of the total food items in these tables. It is possible that the iodine intake values reported here could be underestimations of the true values. However, considering that DRs are the main source for the assessment of dietary intake, it is presumed that the present findings are useful to illustrate the difficulties involved in such a study.

Second, we also need to consider the possibility of a selection bias when generalizing the present findings because of the small sample size $(n=113)$. Because marked differences exist in terms of food culture and dietary habits among different areas of Japan, it has been reported that the average intake of seaweeds differs greatly according to age, family structure, and region (3); thus, further research with a larger sample size from different regions and age groups is needed to confirm the generalizability of our findings in Japan.

Finally, the present study estimated information of the food and nutrient intake on the basis of dietary recall for elderly subjects in 1996-1997. It is possible that the dietary intakes measured did not accurately reflect the 
current situation. Iodine status has traditionally been assessed using the urinary iodide excretion or the goiter rate. Further studies using such measurements over a longer duration are required to assess the frequency of individuals at risk for above UL iodine intake.

In conclusion, the present results indicate that the amount of time for which DRs are required to assess the usual iodine intake would be a year, which was not feasible in this survey and the frequency of iodine intake above UL was approximately once per week. To avoid misperceptions in assessing or interpreting the intermittent intake of nutrients such as iodine, it is necessary to display not only the mean or median iodine intake but also the range of the nutrient intake and the time period in which the upper limit is exceeded.

\section{REFERENCES}

1) WHO. 2007. Assessment of iodine deficiency disorders and monitoring their elimination: A guide for programme managers, p 20. World Health Organization, UNICEF, ICCIDD.

2) Zava TT, Zava DT. 2011. Assessment of Japanese iodine intake based on seaweed consumption in Japan: A literature-based analysis. Thyroid Res 4: 14.

3) Nagataki S. 2008. The average of dietary iodine intake due to the ingestion of seaweeds is $1.2 \mathrm{mg}$ /day in Japan. Thyroid 18: 667-668.

4) Fuse Y, Saito N, Tsuchiya T, Shishiba Y, Irie M. 2007. Smaller thyroid gland volume with high urinary iodine excretion in Japanese schoolchildren: normative reference values in an iodine-sufficient area and comparison with the WHO/ICCIDD reference. Thyroid 17: 145-155.

5) Zimmermann MB, Hess SY, Molinari L, De Benoist B, Delange F, Braverman LE, Fujieda K, Ito Y, Jooste PL, Moosa K, Pearce EN, Pretell EA, Shishiba Y. 2004. New reference values for thyroid volume by ultrasound in iodine-sufficient schoolchildren: a World Health Organization/Nutrition for Health and Development Iodine Deficiency Study Group Report. Am J Clin Nutr 79: 231-237.

6) Wolff J. 1969. Iodide goiter and the pharmacologic effects of excess iodide. Am J Med 47: 101-124.

7) Skare S, Frey HM. 1980. Iodine induced thyrotoxicosis in apparently normal thyroid glands. Acta Endocrinol (Copenh) 94: 332-336.

8) Wolff J, Chaikoff IL. 1948. Plasma inorganic iodide as a homeostatic regulator of thyroid function. J Biol Chem 174: 555-564.

9) Sherwin JR. 1982. Development of regulatory mechanisms in the thyroid: failure of iodide to suppress iodide transport activity. Proc Soc Exp Biol Med 169: 458-462.

10) Food and Nutrition Board, Institute of Medicine. 2001. 8 Iodine, Dietary Reference Intakes for Vitamin A, Vitamin K, Arsenic, Boron, Chromium, Copper, Iodine, Iron, Manganese, Molybdenum, Nickel, Silicon, Vanadium, and Zinc. National Academy Press, Washington DC.

11) DGE, ÖGE, SGE/SVE. 2008. Referenzwerte für die Nährstoffzufuhr. Frunkfurt.

12) Department of Health. 1991. 41 Dietary Reference Values for Food Energy and Nutrients for the United Kingdom: Report of the Panel on Dietary Reference Values of the Committee on Medical Aspects of Food Policy. Report on Health and Social Subjects 41. The Stationery Office (TSO), London.

13) Martin A. 2000. Apports nutritionnels conseilles pour la population française 3 édition. Tec et Doc Lavoisier, Paris.

14) Nordic Council of Ministers. 2001. Nordic Nutrition Recommendations. Køb Publikation, Copenhagen.

15) Ministry of Health Law, Japan. 2009. Dietary Reference Intakes for Japanese 2010. Ministry of Health, Labour and Welfare, Japan, Tokyo (in Japanese).

16) Yoshida M, Kikunaga S, Yamauchi J, Tsubota-Utsugi M, Kodama H, Morita A, Esashi T. 2013. Dietary Reference Intakes for Japanese 2010: Microminerals. J Nutr Sci Vitaminol 59 (Suppl): S91-S102.

17) Nath SK, Moinier B, Thuillier F, Rongier M, Desjeux JF. 1992. Urinary excretion of iodide and fluoride from supplemented food grade salt. Int J Vitam Nutr Res 62 : $66-72$.

18) Ministry of Health, Labour and Welfare, Japan. The National Health and Nutrition Survey of Japan. Ministry of Health, Labour and Welfare, Japan, Tokyo. [Online] Available: http://www.mhlw.go.jp/bunya/kenkou/kenkou_ eiyou_chousa.html [accessed September 10, 2012]

19) Tsuji I, Nishino Y, Ohkubo T, Kuwahara A, Ogawa K, Watanabe Y, Tsubono Y, Bando T, Kanemura S, Izumi Y, Sasaki A, Fukao A, Nishikori M, Hisamichi S. 1998. A prospective cohort study on National Health Insurance beneficiaries in Ohsaki, Miyagi Prefecture, Japan: study design, profiles of the subjects and medical cost during the first year. J Epidemiol 8: 258-263.

20) Ogawa K, Tsubono Y, Nishino Y, Watanabe Y, Ohkubo T, Watanabe T, Nakatsuka H, Takahashi N, Kawamura M, Tsuji I, Hisamichi S. 2003. Validation of a food-frequency questionnaire for cohort studies in rural Japan. Public Health Nutr 6: 147-157.

21) Tsubono Y, Ogawa K, Watanabe Y, Nishino Y, Tsuji I, Watanabe T, Nakatsuka H, Takahashi N, Kawamura M, Hisamichi S. 2001. Food frequency questionnaire and a screening test. Nutr Cancer 39: 78-84.

22) Ministry of Education, Culture, Sports, Science and Technology. 2010. Standard Tables of Food Composition in Japan 2010. Tokyo (in Japanese).

23) Beaton GH, Milner J, Corey P, McGuire V, Cousins M, Stewart E, de Ramos M, Hewitt D, Grambsch PV, Kassim N, Little JA. 1979. Sources of variance in 24-hour dietary recall data: implications for nutrition study design and interpretation. Am J Clin Nutr 32: 2546-2559.

24) Sasaki S. 2013. Dietary Reference Intakes for Japanese 2010: Basic Theories for the Development. J Nutr Sci Vitaminol 59 (Suppl): S9-S17.

25) Katsura E, Nakadou R. 1960. The amount of iodine in a Japanese meal. Eiyo to Shokuryo (J Jpn Soc Food Nutr) 12: 342-344 (in Japanese).

26) Yoshida M. 2013. Excess intake of microminerals: Is the iodine intake of Japanese people excessive. FFI J (Foods and Food Ingredients Journal of Japan) 218: 12-19 (in Japanese).

27) Matsubayashi S, Mukuta T, Watanabe H, Fuchigami H, Taniguchi J, Chinen M, Ninomiya H, Sasaki H. 1998. Iodine-induced hypothyroidism as a result of excessive intake of confectionery made with tangle weed, Kombu, used as a low calorie food during a bulimic period in a patient with anorexia nervosa. Eat Weight Disord 3: 50-52. 
Appendix 1. Iodine reference values $(\mu \mathrm{g} / \mathrm{d})$ for the elderly in selected countries.

\begin{tabular}{lccccc}
\hline & Age group (y) & Mean-2SD & Mean & Mean+2SD & UL \\
\hline Corresponding to DRIs-J & & & EAR & RDA \\
\hline Japan (15) & & NS & 95 & 130 & 2,200 \\
United States of America and Canada (10) & $51-70$ & NS & 95 & 150 & 1,100 \\
Germany and Austria (11) & $51+$ & NS & NS & 180 & 500 \\
United Kingdom (12) & $50+$ & 70 & NS & 140 & NS \\
France (13) & $55+$ & NS & NS & 150 & NS \\
The Nordic countries (14) & $18+$ & 70 & 100 & 150 & NS \\
& & & & & $(600)$
\end{tabular}

SD, standard deviation; DRIs-J, Dietary Reference Intakes for Japanese; EAR, estimated average requirement; RDA, recommended dietary allowance; UL, tolerable upper intake level; NS, not stated. 